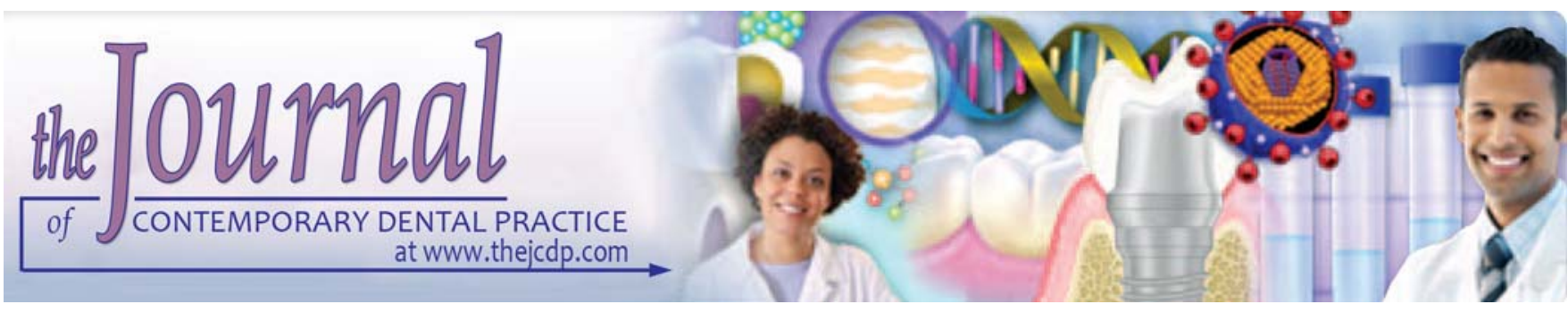

\title{
Managing HIV/Hepatitis Positive Patients: Present approach of Dental Health Care Workers and Students
}

\author{
Nagesh Shinde, Rajendra Baad, Deepak Kumar J Nagpal, Prashant R Prabhu, L Chavan Surekha, Prasad Karande
}

\begin{abstract}
People with HIV/HBsAg in India frequently encounter discrimination while seeking and receiving health care services. The knowledge and attitudes of health care workers (HCWs) influences the willingness and ability of people with HIV/HBsAg to access care, and the quality of the care they receive. The objective of this study was to asses HIV/HBsAg-related knowledge, attitudes and risk perception among students and dental HCWs. A cross-sectional survey was conducted on 250 students and 120 dental HCWs in the form of objective questionnaire. Information was gathered regarding demographic details (age, sex, duration of employment, job category); HIV/ HBsAg-related knowledge and attitudes; risk perception; and previous experience caring for HIV-positive patients. The HCWS in this study generally had a positive attitude to care for the people with HIV/HBsAg. However, this was tempered by substantial concerns about providing care, and the fear of occupational infection with HIV/HBsAg. A continuing dental education program was conducted to resolve all the queries found interfering to provide care to HIV/HBsAg patients. But even after the queries were resolved the care providing capability was not attained. These findings show that even with advanced knowledge and facilities the attitude of dental HCWs and students require more strategic training with regards to the ethics and moral stigma associated with the dreaded infectious diseases (HIV/HBsAg).
\end{abstract}

Keywords: HIV, Hepatitis B, Attitude, Knowledge, Discrimination, Stigma (add).

How to cite this article: Shinde N, Baad R, Nagpal DKJ, Prabhu PR, Surekha LC, Karande P. Managing HIV/Hepatitis Positive Patients: Present approach of Dental Health Care Workers and Students. J Contemp Dent Pract 2012;13(6): 882-885.

\section{Source of support: Nil}

Conflict of interest: None declared

\section{INTRODUCTION}

Dental health workers are considered to be one of the high risk professionals in the health industry. Exposure of contaminants like saliva and blood are routinely observed in the basic dental procedures. Since, the awareness of HIV -
AIDS infection is pronounced, the fear to treat such patients in dental setups is quite common. ${ }^{1} \mathrm{H}$ epatitis-B transmission is considered serious by most of the practioners. These findings have led to pronounced differentiation in treating HIV and HBsAg patients in India. ${ }^{2}$ Nonetheless the oral health care environment has become a helpful setting for early detection, as most lesions present orally during the first stage of the disease. Willingness to treat patients with HIV/AIDS appears to be related to the knowledge of the disease process, its oral manifestations and modes of transmission thus, influencing health care workers' attitudes and behavior toward management of such patient. ${ }^{3} \mathrm{~A}$ sound knowledge is the key to develop right attitude in treating such patients. Aim of the study was to assess knowledge, attitudes and practices among health care providers (HCP) in Sinhgad Dental H ospital Pune. R esults of this study will be utilized in developing a training package targeting knowledge gaps, negative attitudes and practices.

\section{METHODOLOGY}

A cross-sectional study design was conducted in A CPM and Sinhgad Dental College using predesigned and pretested questionnaire for collection of data (Form 1). The study subjects were divided into two groups. Group I (Table 1) comprising of dental health care workers (dental surgeons, nurses, technicians and assistants) and group II (Table 2) representing dental students (IV , III and II year BDS). The sample size was group I containing 120 subjects and group II containing 250 subjects. All the subjects who gave consent to participate in the study were asked to fill up a self administered questionnaire, each correct response was given ' 1 ' score and wrong or no answer was given ' 0 ' score. The knowledge score was highest among the group I MDS category and the lowest among the chair side assistants (Table 3). A mong group II the highest score was among the 
Name:

\section{SURVEY QUESTIONNAIRE}

Age:

Sex:

Professional qualification:

In health profession since:

1. Sexual intercourse can spread HIV/AIDS

2. Contact with urine can spread HIV/AIDS

3. Mosquitoes can spread HIV/AIDS

4. Coughing and sneezing can spread HIV/AIDS

5. HIV/AIDS can spread from an infected women to her child during breastfeeding

6. Contact faces can spread HIV/AIDS

7. Tattooing can spread HIV/AIDS

8. HIV/AIDS can spread when needles are shared by IDUS

9. Contact with saliva can spread HIV/AIDS

10. Do you think, it should be made mandatory to know the HIV status of the partner before marriage?

11. I feel worried about caring for people with HIV/AIDS

12. Doctors, nurses and other health care workers should be allowed to refuse care for people with HIV/AIDS

13. I am willing to work/assist with an operative procedures on patients with HIV/AIDS

14. I would not prefer to care for patients with HIV/AIDS

15. Do you think spillage of blood of HIV/AIDS patient into open mucosal surfaces can lead to infection?

16. Do you think usage of same dental instruments can spread HIV/AIDS

17. It is necessary to take extra infection control precaution for patients with HIV/AIDS

18. Patient with HIV/AIDS need to be nursed separately from other patients

19. All surgical patients should be routinely tested for HIV/AIDS

20. All exodontia patients should be routinely tested for HIV/AIDS

21. All periodontia patients should be routinely tested for HIV/AIDS

22. I worry about catching HIV/AIDS and hepatitis $B$ at work

23. Do you ask for HIV status of patients those who visit your clinic?

24. Needle prick injuries from HIV/AIDS infected individual is $100 \%$ responsible for causing HIV infection.

25. What would you do if you get a needle prick injury during your work with a patient?
a. Immediately do HIV test
c. You will ask for patients HIV test
b. Wash and apply antimicrobials
d. Use post-exposure prophylaxis

26. If a patient in your private clinic discloses that he is HIV positive what would you do?

a. Refer patient to HIV specialty center.

b. You will do yourself with extra precautions and in turn will ask patient to pay extra.

c. Will just give medication without any operative procedures.

d. You will refuse to treat such patient.

27. What will be your attitude toward AIDS patient, if he/she is your wife/husband?
a. You will get separate.
b. You will check your HIV status and will separate, if you are HIV negative.
c. You will except the fact and will provide care, support to your partner.
d. You are sure you will not be under such circumstances.

28. What will be your attitude toward AIDS patients, if he/she is a doctor?
a. You will not except him/her in the area of your work.
b. You will except the fact and will provide care, support to your colleague.
c. Your relation would not change.
d. Cannot answer

29. What oral lesions would you commonly refer patients for HIV screening?
a. Pseudomembraneous candidiasis
b. Unhealing oral ulcers
c. Kaposi's sarcoma/lymphomas
d. Linear gingival erythema

30. Have you ever been associated (met, talked, treated, etc) with HIV/AIDs patients?
a. Yes
b. No
c. You treat all patients as HIV positive
d. Not bothered.

Form 1: Survey questionnaire for evaluation of knowledge and attitude with respect to HIV/HBsAg positive patients 
final year BDS and the lowest from the II year BDS students (Table 4). Majority of the participants' were having a positive attitude in managing HIV/HB SA g positive patients and were willing to manage in the day-to-day practice. The scores had very little variations in group II, and in group I except the assistants most of the participants had no objections in managing such patients (Tables 3 and 4). The scenario on practicality was found to be different; there were no patient's treated, since the groups were not prepared to manage such patients (Table 5). To resolve the queries a continuing dental education program (CDE) was organized conducted by experts in the subject and to make interactive street plays and poster presentation were also included. A feedback form after the CDE was given to all the participants and was found to have resolved the queries with regard to management of seropositive patients. The practicality was then evaluated a year after and still found to be substantially low (Table 6).

\section{DISCUSSION}

The facts regarding transmission of HIV from mosquito bite, feces, saliva were not clear in both the subject groups in addition to this the precautionary measures after exposure, such as from a needle prick injury was lacking indicating the deficiency in knowledge regarding the modes of spread of HIV and postexposure prophylaxis. W ith regard to oral manifestation seen in HIV positive patients the scores were acceptable in both the groups. While the knowledge and attitude were high the practicability was found to be poor like in other studies. ${ }^{4,5}$ This difference could be due to lack of supply of personal protective equipments, belief that it may interfere with their patient care, improper biomedical waste disposal and the most prominent according to our finding is the stigma tow ard such seropositive patients. The fear to treat and lack of confidence due to improper training is the frequent feedback by most of the students especially the final year BDS and the interns. (R eframe since repeating) On the grounds of above findings a CDE program was organized which covered the oral manifestations, medicolegal aspects, postexposure prophylactic measures and universal safety procedures to be followed in routine dental care. But even after the program patients treatment was not performed with all measurements provided confirming the cause to be stigma. This is a common finding in today's modern society and it is unfortunate to observe the stigma quite prominent in a noble profession of health care. This fear and stigma had accompanied the AIDS epidemic from the start. ${ }^{6}$ Though the attitude of DHCW in treating HIV appears to be satisfactory, patients experience a negative result. Numerous studies have documented the attitudes of health care providers toward patients living with HIV (PLHIV) ${ }^{6-8}$ A lthough the literature characterizes the attitudes and behaviors of health care providers as positive and respectful, many studies al so report poor communication between patients and heal th care providers, ${ }^{9}$ which functions as a major barrier in providing proper care for these patients. Research suggests that exploring the experiences of PL HIV with the heal th care system may not only enhance the quality of care that patients receive, but could also improve quality of life for PLHIV. ${ }^{10}$ In addition, the inter-relationship between stigma and other factors known to be associated with adherence to medical treatment among PLHIV needs to befurther demarcated in future studies in order to identify targets for successful intervention programs. ${ }^{11}$

\section{CONCLUSION}

Since its first interception numerous aspects have been studied about HIV /A IDS, but still there is a lack of standard protocol in oral health care management of such patients

Table 1: Categories of dental health care workers in group I

\begin{tabular}{lr}
\hline Group I & No \\
\hline Dental surgeons & \\
MDS & 100 \\
BDS & 50 \\
Nurses & 10 \\
Technicians & 12 \\
Assistants & 8 \\
\hline Total & 180 \\
\hline
\end{tabular}

Table 2: Categories of dental health care workers in group II

\begin{tabular}{ll}
\hline Group II & No. \\
\hline IV year BDS students & 100 \\
III year BDS students & 150 \\
II year BDS students & 150 \\
\hline Total & 400 \\
\hline
\end{tabular}

\begin{tabular}{lcc}
\multicolumn{3}{c}{ Table 3: Knowledge and attitude in group I } \\
\hline Group I & $\begin{array}{c}\text { Knowledge } \\
\text { mean score (\%) }\end{array}$ & $\begin{array}{c}\text { Attitude (willing to treat) } \\
\text { mean score (\%) }\end{array}$ \\
\hline Dental surgeons & & \\
$\quad$ MDS & 82 & 92 \\
$\quad$ BDS & 66 & 94 \\
Nurses & 60 & 91 \\
Technicians & 45 & 95 \\
Assistants & 29 & 79 \\
\hline
\end{tabular}

\begin{tabular}{lcc}
\multicolumn{3}{c}{ Table 4: Knowledge and attitude in group II } \\
\hline Group II & $\begin{array}{c}\text { Knowledge } \\
\text { mean score (\%) }\end{array}$ & $\begin{array}{c}\text { Attitude (willing to treat) } \\
\text { mean score (\%) }\end{array}$ \\
\hline IV year BDS students & 70 & 96 \\
III year BDS students & 73 & 92 \\
II year BDS students & 35 & 91 \\
\hline
\end{tabular}


Managing HIV/Hepatitis Positive Patients: Present approach of Dental Health Care Workers and Students

\begin{tabular}{|c|c|c|c|}
\hline HIV/HBsAg +ve patients & Years & Treatment provided by group I & Treatment provided by group II \\
\hline \multicolumn{4}{|l|}{ HIV-08 } \\
\hline $\begin{array}{l}\text { HBsAg-03 } \\
\text { HIV-10 }\end{array}$ & 2007 & 1-accidentally & 0 \\
\hline $\begin{array}{l}\text { HBsAg-05 } \\
\text { HIV-12 }\end{array}$ & 2008 & 1-accidentally & 0 \\
\hline $\begin{array}{l}\text { HBsAg-05 } \\
\text { HIV-08 }\end{array}$ & 2009 & 0 & 0 \\
\hline HBsAg-05 & 2010 (before 13 F eb ) & 0 & 0 \\
\hline
\end{tabular}

\begin{tabular}{lccc} 
& \multicolumn{2}{c}{ Table 6: Practicability in groups I and II after the CDE program } \\
\hline HIV/HBsAg +ve patients & Year & Treatment provided by group I & Treatment provided by group II \\
\hline HIV-07 & & 0 & 0 \\
HBsAg-04 & 2010 (after 13 Feb) & 0 & 0 \\
\hline
\end{tabular}

which is without discrimination. A more practical exposure in addition to knowledge is required, along with a plan to inculcate a training program as a part of dental curriculum so that the dental professionals can overcome the stigma and gain confidence in managing such patients.

\section{REFERENCES}

1. Gerbert B, M aguire B, B adner V, Altman D, Stone G. Fear of AIDS: Issues for health professional education. AIDS Educ Prev 1989;1:39-52.

2. A sia Pacific Network of people living with HIV/AIDS. AIDS discrimination in A sia 2004. A vailable from http:// www.gnpplus.net/regions/asiapac.html. A ccessed 16J une, 2004.

3. Seacat. JP, Inglehart MS, Habil P. Education about treating patients with HIV infectious AIDS: The student perspective. J Dent Educ 2003;67:630-39.

4. Azodo CC, Ehizele A O, Oboro HO, U moh A. Concerns and attitude of dental students towards HIV infected individuals. Int J Biomed HIth Sci 2010;6(1)

5. Hardie J. Problems associated with providing dental care to patients with HIV -infected and AIDS patients. Oral Surg Oral M ed Oral Pathol 1992;73(2):231-35.

6. Najarkolaei $F R$, et al. Experiences of stigma in healthcare settings among adults living with HIV in the Islamic Republic of Iran. J Int AIDS Society 2010;13:27.

7. Deacon H, B oulle A. Commentary: Factors affecting HIV /AIDSrelated stigma and discrimination by medical professionals. Int J Epidemiol 2007;36:185-86.

8. Reis C, Heisler M, A mowitz LL, M oreland RS, M afeni JO, A nyamele $C$, et al. Discriminatory attitudes and practices by health workers toward patients with HIV/AIDS. Nigeria PIoS $M$ ed 2005;2:743-52.

9. Driessche KV, Sabue M, Dufour W, Behets F, V an Rie A: Training health care workers to promote HIV services for patients with tuberculosis in the D emocratic R epublic of Congo. Hum Resour Health 2009;7:23.

10. K remer H, Ironson G, Schneiderman N, H autzinger M. To take or not to take: Decision-making about antiretroviral treatment in people living with HIV /A IDS. A IDS Patient CareSTDS 2006, 20:335-49.

11. Sayles J N, W ong M D, K insler JJ, M artins D, C unningham WE. The association of stigma with self-reported access to medical care and antiretroviral therapy adherence in persons living with HIV /AIDS. J Gen Internal M ed 2009;24:1101-08.

\section{ABOUT THE AUTHORS}

\section{Nagesh Shinde (Corresponding Author)}

Professor and Head, D epartment of O ral and M axillofacial Pathology ACPM Dental College and Hospital, Dhule, Maharashtra, India e-mail: drnshinde@indiatimes.com

\section{Rajendra Baad}

Professor and Head, D epartment of O ral and M axillofacial Pathology School of Dental Sciences, K rishna D ental College and H ospital, K arad $M$ aharashtra, India

\section{Deepak Kumar J Nagpal}

Reader, Department of Oral and M axillofacial Pathology, Sinhgad Dental College and Hospital, Pune, M aharashtra, India

\section{Prashant R Prabhu}

Senior Lecturer, Department of Oral and M axillofacial Pathology Sinhgad Dental College and Hospital, Pune, M aharashtra, India

\section{Chavan Surekha}

A ssociate Professor, Department of O ral and M axillofacial Pathology B harati V idyapeeth Deemed U niversity, D ental College and Hospital Pune, M aharashtra, India

\section{Prasad Karande}

Senior Lecturer, Department of Oral and M axillofacial Pathology Sinhgad D ental College and Hospital, Pune, M aharashtra, India 